\title{
BMJ Open Does caesarean delivery in the first pregnancy increase the risk for adverse outcome in the second? A registry-based cohort study on first and second singleton births in Norway
}

\author{
Solveig Bjellmo (10 ,1,2 Guro L Andersen, ${ }^{2,3}$ Sissel Hjelle, ${ }^{1}$ Kari Klungsøyr, ${ }^{4,5}$ \\ Lone Krebs, ${ }^{6,7}$ Stian Lydersen, ${ }^{8}$ Pål Richard Romundstad, ${ }^{9}$ Torstein Vik ${ }^{2}$
}

To cite: Bjellmo S, Andersen GL, Hjelle S, et al. Does caesarean delivery in the first pregnancy increase the risk for adverse outcome in the second? A registry-based cohort study on first and second singleton births in Norway. BMJ Open 2020;10:e037717. doi:10.1136/ bmjopen-2020-037717

- Prepublication history and additional material for this paper are available online. To view these files, please visit the journal online (http://dx.doi org/10.1136/bmjopen-2020037717).

Received 13 February 2020 Revised 13 July 2020 Accepted 16 July 2020

Check for updates

(c) Author(s) (or their employer(s)) 2020. Re-use permitted under CC BY-NC. No commercial re-use. See rights and permissions. Published by BMJ.

For numbered affiliations see end of article.

Correspondence to

Dr Solveig Bjellmo;

solveigbjellmo@gmail.com

\section{ABSTRACT}

Objective To explore if newborns in the second pregnancy following a previous caesarean delivery (CD) have higher risk of perinatal mortality or cerebral palsy than newborns in pregnancies following a previous vaginal delivery (VD). Design Cohort study with information from the Medical Birth Registry of Norway and the Cerebral Palsy Registry of Norway.

Setting Births in Norway.

Participants 294598 women with their first and second singleton delivery during 1996-2015.

Main outcome measures Stillbirth, perinatal mortality, neonatal mortality and cerebral palsy.

Results Among 294598 included women, 42962 (15\%) had a CD in their first pregnancy while 251636 (85\%) had a VD. Compared with the second delivery of mothers with a previous VD, the adjusted OR (adjOR), for stillbirth in the second pregnancy following a previous CD was 1.45 , $95 \% \mathrm{Cl} 1.22$ to 1.73 ; for perinatal death the adjOR was 1.42 (1.22 to 1.73) and for neonatal death 1.13 (0.86 to 1.49). Among children who survived the neonatal period, the adjOR for cerebral palsy was 1.27 (0.99 to 1.64). Secondary outcomes, including small for gestational age, preterm and very preterm birth, uterine rupture and placental complications (eg, postpartum haemorrhage and pre-eclampsia) were more frequent in the subsequent pregnancy following a previous CD compared with a previous VD, in particular for uterine rupture adjOR 86.7 (48.2 to 156.1). Adjustment for potential confounders attenuated the ORs somewhat, but the excess risk in the second pregnancy persisted for all outcomes.

Conclusion A previous CD was in this study associated with increased risk for stillbirth and perinatal death compared with a previous VD. Although less robust, we also found that a previous CD was associated with a slightly increased risk of cerebral palsy among children surviving the neonatal period. The aetiology behind these associations needs further investigation.

\section{INTRODUCTION}

Between year 2000 and 2015, the number of caesarean deliveries (CD) increased from 16 to 29.7 million deliveries worldwide. ${ }^{1}$ Moreover,
Strengths and limitations of this study

Prospectively recording of high-quality data in the two national registers.

- Large number of births.

- Misclassification may occur for some of the clinical outcomes.

- Limited ability to address explanatory factors.

in 2008 , WHO estimated that 6.2 million not medically indicated CDs were performed each year. ${ }^{2}$ The 'ideal' CD rate has been debated for many years, and different studies have argued that a higher rate than $15 \%$ would not improve maternal and neonatal outcomes, ${ }^{3-5}$ while others have suggested national CD rate up to $19 \% .^{6}$ However, many middle-income and high-income countries have $\mathrm{CD}$ rates of $30 \%-50 \%{ }^{7}$ Although the risk for severe acute complications of CD is low in these countries, ${ }^{8}$ concerns regarding long-term complications, both for the mother and her child have been raised, also in subsequent pregnancy. ${ }^{910}$

In Norway, a country with a $\mathrm{CD}$ rate of $16 \%$, approximately $65 \%$ of the total number are emergency CDs. ${ }^{11}$ However, in deliveries when planned $\mathrm{CD}$ is recommended to prevent potentially adverse outcomes of vaginal delivery (VD), these advantages should be weighed against potential long-term complications, including those in later pregnancies. This is particularly important when the absolute risk for acute complications during VD is low, such as in breech VD. ${ }^{12}$ Studies have also reported higher risk for placental complications and uterine rupture in pregnancies following a previous CD. ${ }^{1013} 14$ These complications are also associated with higher risk for delayed neurodevelopment and cerebral 
palsy in the offspring. ${ }^{15}{ }^{16} \mathrm{~A}$ balanced information on potential long-term consequences of $\mathrm{CD}$ is even more important when the mother requests her baby to be delivered by $\mathrm{CD}$, but where medical evidence to support this choice is limited. ${ }^{17}$

On this background, the main aim of the present study was to explore if offspring in deliveries following a previous $\mathrm{CD}$, have higher risk for perinatal death or cerebral palsy than offspring where the mother had a previous VD. As secondary outcomes, we also assessed the risks for placental complications, uterine rupture, preterm birth, fetal growth restriction and neonatal morbidity in the offspring following an earlier CD compared with those following a previous VD.

\section{METHODS}

In this population-based cohort study, including all births in Norway between 1996 and 2015 and information regarding pregnancy, delivery and the neonatal period was retrieved from the Medical Birth Registry of Norway (MBRN). This information was combined with information on a diagnosis of cerebral palsy recorded in the Cerebral palsy Registry of Norway (CPRN). The unique 11-digit personal identification number for every Norwegian citizen was used to link information from the two registers and made it possible to follow the women throughout all her pregnancies. Registration in the MBRN has been compulsory since 1967 with prospectively recorded information during pregnancy and at birth, including demographic variables, information on maternal health before and during pregnancy, interventions and complications during pregnancies, delivery and neonatal outcomes (including stillbirth). The CPRN is an informed consentbased national quality register established in 2006 and aims to record detailed information on all children with cerebral palsy born in Norway since 1996. Paediatricians at the neurohabilitation centres in Norway complete the information of each child using a standardised form. A validation study indicated that $\sim 80 \%$ of the children with cerebral palsy born in Norway in 1996-2007 had detailed information in the CPRN. ${ }^{18}$ Later validations have suggested that the completeness is around $90 \%$ in recent years (annual reports of the CPRN).

Eligible for inclusion in this population-based study was women who delivered their first and second singleton child in Norway during 1996-2015. We excluded offspring who were born before 22 completed weeks of gestation and had a birth weight below $500 \mathrm{~g}$. The offsprings were linked to their mothers by means of the national identification numbers, yielding maternal sibship files with the mother as the observation unit.

\section{Study variables}

The exposure variable was $\mathrm{CD}$ in the first pregnancy, regardless of whether this was emergency or planned. The reference group comprised mothers who delivered their first child vaginally (VD).
The predefined main outcome measures were stillbirth (antepartum and intrapartum and those with unspecified timing of death), perinatal mortality (stillbirth and deaths during first week of life), early neonatal mortality (deaths during first week of life), neonatal mortality (deaths during first 28 days of life) and cerebral palsy. In the CPRN, the diagnosis cerebral palsy is confirmed at 5 years of age according to the definition and classification proposed by the Surveillance of Cerebral Palsy in Europe. ${ }^{19}$

Secondary outcomes were preterm birth, evidence of fetal growth restriction, uterine rupture and placental complications such as placenta previa, placental abruption, abnormal invasive placenta, pre-eclampsia and postpartum haemorrhage. Preterm birth was defined as a birth before 37 weeks, and very preterm birth as a birth before 32 completed weeks of gestation. Evidence of fetal growth restriction was assessed by the proxy small for gestational age (SGA) defined by a birth weight below-2 SD of the population mean weight for GA, adjusted for sex. ${ }^{20}$

Other variables extracted from the MBRN were maternal and pregnancy-related disorders such as pregestational diabetes, gestational diabetes and pre-eclampsia. For the purpose of the present study, we included gestational diabetes, and diabetes mellitus type 1 and 2 in the composite variable 'diabetes', while pre-eclampsia included mild, severe and unspecified pre-eclampsia, in addition to eclampsia and haemolysis, elevated liver enzymes, low platelets. Maternal age, birth year, smoking and congenital anomalies were also extracted. Information on smoking, recorded in the MBRN since December 1998, is based on information from 'the antenatal chart', a standardised form intended for clinical use, carried by the mother to each antenatal visit and completed by midwives and doctors responsible for the antenatal care. The mother is asked about smoking habits (daily smoking, occasionally or not at all) at first antenatal visit and at the end of the pregnancy. However, in contrast to all other variables registered in the MBRN, the mother may decline that her information on smoking is reported to the MBRN. Thus, information on smoking is missing for a subsample of mothers (around 12\% in 1999-2000, nearly 20\% in 2004-2007 and decreasing to less than $10 \%$ since 2015). For those with smoking information registered, we defined smokers as mothers who indicated that they smoked daily or occasionally either at the beginning or at the end of the pregnancy or both. Non-smokers were mothers who responded that they did not smoke during the pregnancy.

Gestational age was based on ultrasound examination before 20 weeks of gestation in $84 \%$ of the pregnant women, while in the remaining it was calculated from the last menstrual period.

\section{Statistical analyses}

Differences in proportions between groups were analysed using the $\mathrm{X}^{2}$ test, and differences in means for continuous 
variables were analysed using the Student's t-test not assuming equal variances.

Logistic regression analyses were used to calculate crude and adjusted ORs (OR) with 95\% CIs for adverse outcomes of the second delivery following a $\mathrm{CD}$ in the first, compared with the outcomes of second deliveries following a first VD.

Potential confounders included in the multivariable analyses were selected based on availability, a priori knowledge and directed acyclic graphs methodology. ${ }^{21}$ These variables included pregnancy-related disorders (such as diabetes and pre-eclampsia), maternal age, birth year, SGA and congenital anomalies all recorded at the first delivery.

Since there is a risk of recurrence of adverse outcomes, such as stillbirth, perinatal death, preterm birth, fetal growth restriction and pre-eclampsia from one delivery to the next, ${ }^{22-24}$ we included complications in the first pregnancy that were defined as an adverse outcome in the second, as potential confounders. These complications may also affect the choice of mode of delivery in the first pregnancy, leading to potential confounding by indication, partly adjusted for in the logistic regression analyses described above. In addition, we also assessed confounding by indication in stratified analyses within subgroups of pregnancies with high and low risk for adverse outcomes. ${ }^{25}$ The high-risk group comprised women with any complication in the first pregnancy that in the second pregnancy were considered as primary or secondary outcomes (stillbirth, perinatal mortality, neonatal mortality, SGA, placenta previa, postpartum haemorrhage, uterine rupture, placental abruption, preterm delivery and pre-eclampsia). The low-risk group included mothers without any of the specified primary or secondary outcomes in the first delivery, and where the first infant was born at term.

In separate analyses, maternal smoking was explored as a potential additional confounder in the population of mothers who had available information on smoking, with first deliveries from 1999.

Moreover, the birth intervals between pregnancies are likely to be shorter in mothers with a perinatal loss than in mothers whose first baby survived. ${ }^{26}$ Mothers with a first delivery towards the end of the study period will have shorter interpregnancy intervals, and therefore, be more likely to have a first perinatal loss, and thus at increased risk for a recurrent second loss. In order to assess this possible bias, we performed a sensitivity analysis where we excluded women who had their first birth in 2012 or later, since these women had interpregnancy interval less than 4 years. Analyses from the MBRN show that $95 \%$ of women with two or more births, have their second child within 7 years following the first. ${ }^{27}$ IBM SPSS Statistics V.25 was used for data analyses.

\section{Patient involvement}

Patients were not involved in setting the research question or the outcome measures nor were they involved in the design and implementation of the study. There are currently no plans to involve patients in dissemination.

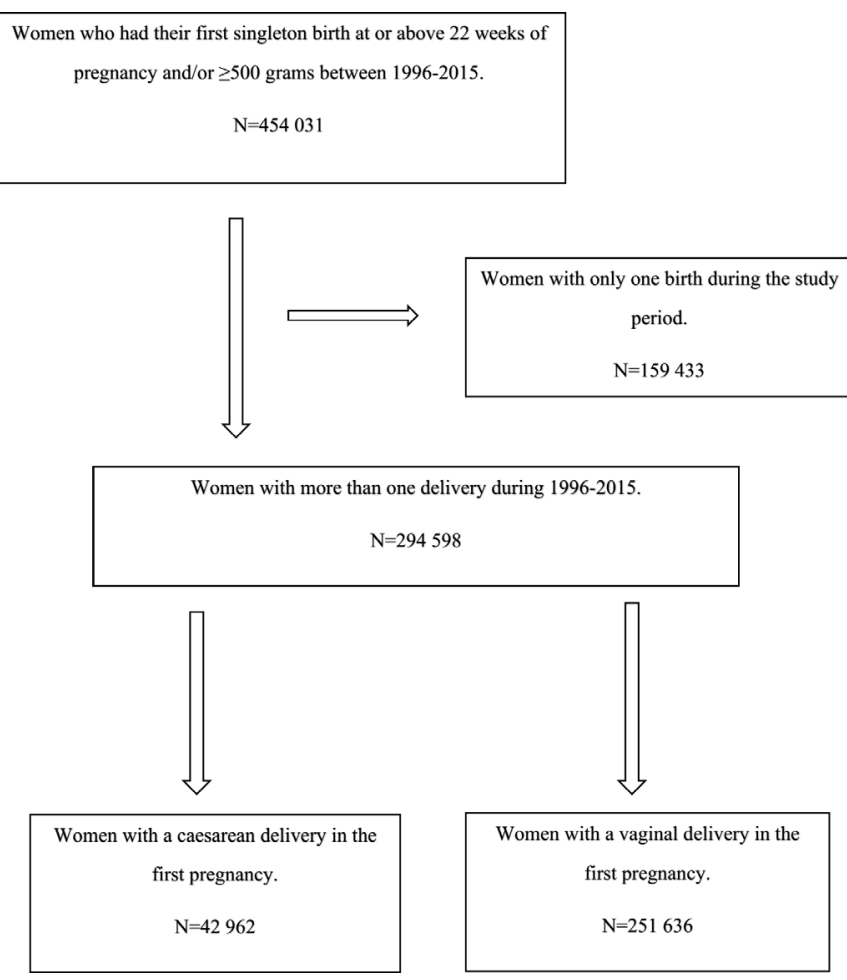

Figure 1 Flow chart of the study population. Only the first (exposure) and second (outcome) delivery of these women were included in the study.

\section{RESULTS}

During the study period, 454031 mothers gave birth to a singleton as their first birth, but 159433 had only one delivery. Among the remaining 294598 mothers, 42962 (15\%) had a CD in their first pregnancy while $251636(85 \%)$ had a VD (figure 1).

Characteristics of the mothers and their babies, as well as adverse outcomes in the first pregnancy when mothers had a caesarean or VD are shown in table 1 . The table shows that intrapartum stillbirth and neonatal loss occurred more frequently, whereas antepartum and total stillbirth occurred less frequently in the group of mothers with $\mathrm{CD}$ than mothers with a VD. Perinatal mortality did not differ between the two groups. A higher proportion of mothers in the $\mathrm{CD}$ group than in the VD group had pre-eclampsia and diabetes and more children were SGA, had congenital anomalies and were later diagnosed with cerebral palsy (table 1).

In their second delivery, approximately half of the women with a previous $\mathrm{CD}$ also had $\mathrm{CD}$ in their subsequent pregnancy, compared with 6\% among those with a previous VD (table 2). Gestational age and mean birth weight were slightly lower and congenital anomalies, Apgar scores below 7 after 5 min and being transferred to the NICU were more common in the group with a previous CD (table 2).

When adjusting for potential confounders, the second infant of mothers with a previous $\mathrm{CD}$ had higher odds for antepartum and intrapartum stillbirth, total stillbirth and perinatal death compared with the second infant of a mother with a previous VD (table 3). The adjusted OR for early neonatal mortality was 1.27 (95\% CI 0.92 to 1.73 ), for 
Table 1 Maternal and infant characteristics and adverse outcomes in the first pregnancy of 42962 women who had a caesarean and 251636 women who had a vaginal delivery (VD) during 1996-2015

\begin{tabular}{|c|c|c|}
\hline & CD & VD \\
\hline Age, mean (SD) & $27.8(4.7)$ & $26.5(4.5)$ \\
\hline \multicolumn{3}{|l|}{ Smoking, N (\%) } \\
\hline $\begin{array}{l}\text { Information about } \\
\text { smoking in the } \\
\text { MBRN }\end{array}$ & 29229 (68.0) & 170040 (67.6) \\
\hline $\begin{array}{l}\text { Smoked during } \\
\text { pregnancy }\end{array}$ & $4571(15.6)^{\star}$ & $27273(16.0)^{\star}$ \\
\hline Pre-eclampsia N (\%) & $5348(12.4)$ & $9346(3.7)$ \\
\hline Diabetes, N (\%) & $1366(3.2)$ & 2977 (1.2) \\
\hline Placenta previa N (\%) & $474(1.1)$ & $52(0.02)$ \\
\hline Placenta abruption $\mathrm{N}$ & $865(2.0)$ & $258(0.1)$ \\
\hline
\end{tabular}

(\%)

\begin{tabular}{lcc}
$\begin{array}{l}\text { Uterine rupture N (\%) } \\
\text { Start of delivery, N (\%) }\end{array}$ & $5(0.01)$ & $5(0.002)$ \\
\hline $\begin{array}{l}\text { Spontaneous } \\
\text { Induced }\end{array}$ & $18568(43.2)$ & $215243(85.5)$ \\
$\begin{array}{l}\text { Caesarean delivery } \\
\text { (CD) }\end{array}$ & $13768(33.0)$ & $36393(14.5)$ \\
$\begin{array}{l}\text { Gestational age at } \\
\text { birth in weeks, mean }\end{array}$ & $39.0(2.9)$ & 0 \\
\hline
\end{tabular}

birth in weeks, mean

(SD)

\begin{tabular}{|c|c|c|}
\hline $\begin{array}{l}\text { Birth weight in grams, } \\
\text { mean (SD) }\end{array}$ & 3401 (810) & 3477 (524) \\
\hline \multicolumn{3}{|l|}{ Sex, N (\%) } \\
\hline Female & $19597(46.0)$ & 123230 (49.0) \\
\hline SGA†, N (\%) & $1995(5.0)$ & $4823(2.0)$ \\
\hline $\begin{array}{l}\text { Congenital anomalies, } \\
\mathrm{N}(\%)\end{array}$ & $3004(7.0)$ & $10386(4.1)$ \\
\hline Total stillbirth, N (\%) & $110(0.3)$ & $1408(0.6)$ \\
\hline $\begin{array}{l}\text { Antepartum stillbirth, } \\
\mathrm{N}(\%)\end{array}$ & $55(0.1)$ & $1039(0.4)$ \\
\hline $\begin{array}{l}\text { Intrapartum stillbirth, } \\
\mathrm{N}(\%)\end{array}$ & $28(0.1)$ & $102(0.04)$ \\
\hline $\begin{array}{l}\text { Perinatal mortality, N } \\
(\%)\end{array}$ & $301(0.7)$ & $1714(0.7)$ \\
\hline $\begin{array}{l}\text { Early neonatal } \\
\text { mortality, N (\%) }\end{array}$ & $191(0.4)$ & $306(0.1)$ \\
\hline $\begin{array}{l}\text { Neonatal mortality, N } \\
(\%)\end{array}$ & $262(0.6)$ & $399(0.2)$ \\
\hline Cerebral palsy, N (\%) & $189(0.4)$ & $350(0.1)$ \\
\hline \multicolumn{3}{|c|}{ Apgar score after five min $\neq, \mathrm{N}(\%)$} \\
\hline $0-3$ & $406(0.9)$ & $1662(0.7)$ \\
\hline $4-6$ & $2314(5.4)$ & $5972(2.3)$ \\
\hline $7-10$ & $40142(93.7)$ & $243221(97.0)$ \\
\hline \multicolumn{3}{|l|}{ Transferred NICU, N (\%) } \\
\hline Yes & 8965 (26.0) & $18971(10.0)$ \\
\hline
\end{tabular}

Continued
Table 1 Continued

\section{CD}

VD

*Percentage of mothers with information on smoking (available in the MBRN since 1999).

†971 (2.3\%) deliveries with missing information about SGA in the CD group and $5280(2.1 \%)$ in the VD group.

$\ddagger 100(0.2 \%)$ deliveries with missing information about Apgar score in the CD group and $781(0.3 \%)$ in the VD group.

MBRN, Medical Birth Registry of Norway; NICU, neonatal intensive care unit; SGA, small for gestational age.

Table 2 Maternal and infant characteristics, including mode of delivery and adverse outcomes in the second pregnancy of 42962 who had a caesarean and 251636 who had a vaginal delivery in their first pregnancy (CD vs VD) during 1996-2015

\begin{tabular}{|c|c|c|c|}
\hline & Previous CD & Previous VD & $P$ value \\
\hline $\begin{array}{l}\text { Mothers age in } \\
\text { years, mean (SD) }\end{array}$ & $31.1(4.6)$ & $29.9(4.4)$ & $<0.001$ \\
\hline Diabetes, N (\%) & $2095(4.9)$ & $4834(1.9)$ & $<0.001$ \\
\hline \multicolumn{4}{|l|}{ Start of delivery, N (\%) } \\
\hline Spontaneous & 22707 (53.0) & 211165 (84.0) & \\
\hline Induced & $7179(17.0)$ & 30895 (12.0) & $<0.001$ \\
\hline CD & $13074(30.0)$ & $9570(4.0)$ & \\
\hline \multicolumn{4}{|c|}{ Mode of delivery*, N (\%) } \\
\hline Vaginal delivery & 20826 (48.0) & $235372(94.0)$ & $<0.001$ \\
\hline CD & $22136(52.0)$ & $16264(6.0)$ & \\
\hline $\begin{array}{l}\text { Gestational age at } \\
\text { birth in weeks mean } \\
\text { (SD) }\end{array}$ & $39.1(2.0)$ & $39.5(1.7)$ & $<0.001$ \\
\hline $\begin{array}{l}\text { Birth weight in } \\
\text { grams mean (SD) }\end{array}$ & 3577 (613) & $3630(541)$ & $<0.001$ \\
\hline $\begin{array}{l}\text { Congenital } \\
\text { anomalies, N (\%) }\end{array}$ & $2007(4.7)$ & $9537(3.8)$ & $<0.001$ \\
\hline \multicolumn{4}{|l|}{ Sext, N (\%) } \\
\hline Female & 20958 (49.0) & 122307 (49.0) & 0.50 \\
\hline \multicolumn{4}{|c|}{ Apgar score after $5 \min \ddagger, \mathrm{N}(\%)$} \\
\hline $0-3$ & $292(1.0)$ & $1048(0.4)$ & \\
\hline $4-6$ & $1196(3.0)$ & 2955 (1.2) & $<0.001$ \\
\hline $7-10$ & 41407 (96.0) & $247028(98.4)$ & \\
\hline \multicolumn{4}{|c|}{ Transferred NICU, N (\%) } \\
\hline Yes & $5424(13.0)$ & $16502(7.0)$ & $<0.001$ \\
\hline
\end{tabular}

*2 $(0.005 \%)$ deliveries with missing information about start of delivery in the previous CD group and $6(0.002 \%)$ in the previous VD group.

$\dagger 12(0.005 \%)$ deliveries with missing information about sex in the previous VD group.

$\ddagger 67(0.16 \%)$ deliveries with missing information about Apgar score in the previous CD group and $605(0.24 \%)$ in the previous VD group.

$\mathrm{CD}$, caesarean delivery; NICU, neonatal intensive care unit; VD, vaginal delivery. 
Table 3 OR with 95\% Cls for adverse outcomes in the second pregnancy of 42962 mothers who had a caesarean delivery (CD) in the first pregnancy compared with 251636 mothers who had a previous vaginal delivery (VD

\begin{tabular}{|c|c|c|c|c|}
\hline \multirow[t]{2}{*}{ 1st birth } & \multicolumn{4}{|c|}{ 2nd birth } \\
\hline & \multicolumn{2}{|c|}{ Antepartum stillbirth } & $\begin{array}{l}\text { Crude OR } \\
(95 \% \mathrm{Cl})\end{array}$ & $\begin{array}{l}\text { Adjusted OR } \\
(95 \% \mathrm{Cl})^{*}\end{array}$ \\
\hline CD 1st & $\mathrm{N}(\%)$ & $128(0.3)$ & $\begin{array}{l}1.44(1.19 \text { to } \\
1.75)\end{array}$ & $\begin{array}{l}1.33 \text { (1.08 to } \\
1.63)\end{array}$ \\
\hline \multirow[t]{2}{*}{ VD 1st } & $\mathrm{N}(\%)$ & $520(0.2)$ & 1.0 (ref) & 1.0 (ref) \\
\hline & \multicolumn{4}{|c|}{ Intrapartum stillbirth } \\
\hline CD 1st & $\mathrm{N}(\%)$ & $14(0.03)$ & $\begin{array}{l}1.58(0.87 \text { to } \\
2.85)\end{array}$ & $\begin{array}{l}1.84(1.00 \text { to } \\
3.38)\end{array}$ \\
\hline \multirow[t]{2}{*}{ VD 1st } & $\mathrm{N}(\%)$ & $52(0.02)$ & 1.0 (ref) & 1.0 (ref) \\
\hline & \multicolumn{4}{|c|}{ Stillbirth (total) $†$} \\
\hline CD 1st & $\mathrm{N}(\%)$ & $179(0.4)$ & $\begin{array}{l}1.52(1.29 \text { to } \\
1.79)\end{array}$ & $\begin{array}{l}1.45(1.22 \text { to } \\
1.73)\end{array}$ \\
\hline \multirow[t]{2}{*}{ VD 1st } & $\mathrm{N}(\%)$ & $693(0.3)$ & 1.0 (ref) & 1.0 (ref) \\
\hline & \multicolumn{4}{|c|}{ Perinatal mortality } \\
\hline CD 1st & $\mathrm{N}(\%)$ & $231(0.5)$ & $\begin{array}{l}1.47(1.27 \text { to } \\
1.70)\end{array}$ & $\begin{array}{l}1.42(1.22 \text { to } \\
1.65)\end{array}$ \\
\hline \multirow[t]{2}{*}{ VD 1st } & $\mathrm{N}(\%)$ & $921(0.4)$ & 1.0 (ref) & 1.0 (ref) \\
\hline & \multicolumn{4}{|c|}{ Early neonatal mortality } \\
\hline CD 1st & $\mathrm{N}(\%)$ & $52(0.1)$ & $\begin{array}{l}1.34(0.99 \text { to } \\
1.81)\end{array}$ & $\begin{array}{l}1.27(0.92 \text { to } \\
1.73)\end{array}$ \\
\hline \multirow[t]{2}{*}{ VD 1st } & $\mathrm{N}(\%)$ & $228(0.1)$ & 1.0 (ref) & 1.0 (ref) \\
\hline & \multicolumn{4}{|c|}{ Neonatal mortality } \\
\hline CD 1st & $\mathrm{N}(\%)$ & $68(0.2)$ & $\begin{array}{l}1.24(0.95 \text { to } \\
1.61)\end{array}$ & $\begin{array}{l}1.13(0.86 \text { to } \\
1.49)\end{array}$ \\
\hline \multirow[t]{2}{*}{ VD 1st } & $\mathrm{N}(\%)$ & $321(0.1)$ & 1.0 (ref) & 1.0 (ref) \\
\hline & \multicolumn{4}{|c|}{ Cerebral palsy } \\
\hline CD 1st & $\mathrm{N}(\%)$ & $83(0.2)$ & $\begin{array}{l}1.44(1.13 \text { to } \\
1.83)\end{array}$ & $\begin{array}{l}1.27(0.99 \text { to } \\
1.64)\end{array}$ \\
\hline VD 1st & $\mathrm{N}(\%)$ & $338(0.1)$ & 1.0 (ref) & 1.0 (ref) \\
\hline
\end{tabular}

Singleton deliveries during 1996-2015.

*Adjusted for maternal age, birth year, pregnancy-related disorders (pre-eclampsia and diabetes), SGA, congenital anomalies, uterine rupture, placenta previa, placental abruption in first pregnancy and the studied outcome in the first pregnancy.

tincluding stillbirths with unknown timing of death.

SGA, small for gestational age.

neonatal mortality the OR was 1.13 (95\% CI 0.86 to 1.49 ) and for cerebral palsy OR was 1.27 (95\% CI 0.99 to 1.64) (table 3).

When these associations were studied among women with high $(n=78056)$ and low $(n=211$ 313) risk for adverse outcomes, the results were essentially the same as in the total study population (data are not shown).

All secondary outcomes, except abnormal invasive placenta, were more frequent in the subsequent pregnancy of women with a previous CD than among those with a previous VD (table 4 ). Most of these associations were attenuated in multivariable analyses, but the main findings persisted.

In the subsample of 199269 women where information about smoking was available (68\% of the total study population), the results regarding antepartum and intrapartum stillbirth, overall stillbirth, perinatal early and neonatal mortality persisted, but were slightly attenuated in the multivariable analyses (see online supplementary table 1). The crude OR for cerebral palsy was also unchanged but was reduced in the multivariable analyses to 1.23 (95\% CI 0.90 to 1.67 ). However, adding smoking as a potential confounder to the other confounders did not change the adjusted OR neither for primary nor for the secondary outcomes (see online supplementary tables 1 and 2)

In the sensitivity analyses excluding women who had their first birth in 2012 or later (leaving 274041 women for analysis), the results were nearly identical to the results in the total population. In this subsample, $39812(15 \%)$ had a CD in their first pregnancy and $234229(85 \%)$ had a VD (see online supplementary tables 3 and 4).

\section{DISCUSSION}

In this population-based cohort study in Norway, we found increased risk for stillbirth, perinatal death and cerebral palsy in the second pregnancy of mothers who had a CD in their first pregnancy, compared with mothers who had a VD in their first pregnancy. In contrast we did not find a higher risk for neonatal mortality, although there was a trend towards increased risk for early neonatal mortality. Also, growth restriction, preterm delivery, pre-eclampsia, placental complications, postpartum haemorrhage and especially uterine rupture were increased in pregnancies following a $\mathrm{CD}$.

\section{Strength and limitations}

The strength of this study is the large number of births based on mandatory registration and thus minimal risk of selection bias. The prospectively collected data from the MBRN and the CPRN, and the ability to link births to their mothers by the identification numbers enabled complete analyses of the first and second births to all mothers giving birth in 1996-2015. We restricted the analyses to singletons, since both CD and the studied outcomes are more frequent in multiple pregnancies. Moreover, the main findings persisted when adjusted for potential confounders in multivariable analyses, and when we assessed confounding by indication in analyses restricted to mothers with high and low risk of adverse outcomes. In these latter analyses, the main findings persisted in both groups, suggesting that confounding by indication was less likely. Finally, in the subpopulation with information on smoking, the main results also persisted.

A potential selection bias of the study population may arise from the fact that women with a perinatal loss in their first pregnancy tend to proceed to their second pregnancy earlier than women without such an event, 
Table 4 OR with 95\% Cls for adverse secondary outcomes in the second pregnancy of 42962 mothers who had a caesarean delivery $(C D)$ in the first pregnancy compared with 251636 mothers who had a previous vaginal delivery (VD)

\begin{tabular}{|c|c|c|c|c|}
\hline \multirow[t]{2}{*}{ 1st birth } & \multicolumn{4}{|c|}{ 2nd birth } \\
\hline & \multicolumn{2}{|c|}{ Small for gestational age* } & Crude OR (95\% Cl) & Adj OR (95\% Cl)† \\
\hline CD 1st & $N(\%)$ & $636(1.5)$ & $1.63(1.49$ to 1.78$)$ & $1.32(1.20$ to 1.45$)$ \\
\hline VD 1st & \multicolumn{4}{|c|}{ Preterm birth $\ddagger$} \\
\hline CD 1st & $N(\%)$ & 2647 (6.2) & $1.72(1.64$ to 1.80$)$ & $1.18(1.12$ to 1.24$)$ \\
\hline VD 1st & \multicolumn{4}{|c|}{ Very preterm birth $\neq$} \\
\hline CD 1st & $N(\%)$ & $570(1.3)$ & 1.97 (1.79 to 2.17$)$ & $1.29(1.16$ to 1.44$)$ \\
\hline \multirow[t]{2}{*}{ VD 1st } & $N(\%)$ & $1703(0.7)$ & 1.0 (ref) & 1.0 (ref) \\
\hline & \multicolumn{4}{|c|}{ Postpartum haemorrhage } \\
\hline CD 1st & $N(\%)$ & $12232(28)$ & 2.76 (2.70 to 2.83$)$ & 2.32 (2.26 to 2.38$)$ \\
\hline CD 1st & $N(\%)$ & $292(0.7)$ & 2.60 (2.27 to 2.99$)$ & 2.33 (2.01 to 2.70$)$ \\
\hline \multirow[t]{2}{*}{ VD 1st } & $N(\%)$ & $660(0.3)$ & 1.0 (ref) & 1.0 (ref) \\
\hline & \multicolumn{4}{|c|}{ Placental abruption } \\
\hline CD 1st & $N(\%)$ & $282(0.7)$ & 2.48 (2.16 to 2.86$)$ & 2.14 (1.84 to 2.49$)$ \\
\hline \multirow[t]{2}{*}{ VD 1st } & $N(\%)$ & $668(0.3)$ & 1.0 (ref) & 1.0 (ref) \\
\hline & \multicolumn{4}{|c|}{ Abnormal invasive placenta } \\
\hline CD 1st & $N(\%)$ & $131(0.3)$ & $1.14(0.95$ to 1.38$)$ & $1.00(0.82$ to 1.21$)$ \\
\hline \multirow[t]{2}{*}{ VD 1st } & $N(\%)$ & $672(0.3)$ & 1.0 (ref) & 1.0 (ref) \\
\hline & \multicolumn{4}{|c|}{ Uterine rupture } \\
\hline
\end{tabular}

Singleton deliveries during 1996-2015.

*308 $(0.7 \%)$ deliveries with missing information on SGA in the caesarean group and $2000(0.8 \%)$ in the vaginal group.

†Adjusted maternal age, birth year, pregnancy-related disorders (pre-eclampsia and diabetes), SGA and congenital anomalies, uterine rupture, placenta previa, placental abruption in first pregnancy and the studied outcome in the first pregnancy.

$\ddagger 306(0.7 \%)$ deliveries with missing information on GA in the caesarean group and $1958(0.8 \%)$ in the vaginal group.

GA, gestational age; SGA, small for gestational age.

thereby artificially increasing the proportion of women with losses in their second pregnancy (due to the known recurrence risk of perinatal losses). Since the implications of this selection bias is unclear, we performed sensitivity analyses where we excluded women who had their first birth in 2012 or later, and hence had an interpregnancy interval shorter than 4 years. Moreover, in the population born after 2012 there may be some underreporting of cases with cerebral palsy, since this diagnosis is reported to the CPRN at age 5 years, and since there may be some delay in the registration. Nonetheless, all results were essentially unchanged.

Other limitations of this study are related to potential misclassification of both exposure and outcome. The data on mortality and delivery mode are variables with high quality and are unlikely to be misclassified. ${ }^{28}$ For the secondary outcomes, both pre-eclampsia, SGA and preterm delivery are variables with high quality, ${ }^{29}$ while the validity for placenta previa and placental abruption has not been studied. In addition, inconsistent definitions may have led to some misclassification of uterine rupture and abnormal invasive placenta. ${ }^{30}$

Further limitations are related to unmeasured confounders, as well as to potential confounders with limited available data, such as body mass index and weight change during the pregnancy.

\section{Comparison with other studies}

Our findings regarding excess risk for stillbirth in subsequent pregnancies after a previous $\mathrm{CD}$ is consistent with 
several other studies. ${ }^{31-34}$ In a retrospective cohort study and meta-analysis published in 2015, the authors found an association between previous $\mathrm{CD}$ and the risk for antepartum stillbirth in the second pregnancy with a pooled HR 1.40 (95\% CI 1.10 to 1.77$),{ }^{35}$ similar to our results.

Another systematic review and a meta-analysis published in 2018 reported no clear association of mode of delivery with perinatal death comparing previous $\mathrm{CD}$ with previous $\mathrm{VD},{ }^{9}$ as opposed to the results of the present study. However, this meta-analysis included only two studies with considerably smaller populations than the present study and in one of them, the estimated OR for perinatal death was 1.29 (95\% CI 0.94 to 1.79$),{ }^{32}$ more in line with our study. Moreover, an older study not included in the meta-analysis but with a population of the same size as our study, found increased risk for perinatal death among children born by a mother with a previous CD compared with previous VD (RR 1.33, 95\% CI 1.10 to 1.62$){ }^{36}$

We have not found other studies addressing the risk of cerebral palsy in deliveries following a previous CD.

Regarding the secondary outcomes, the increased risks of SGA, preterm birth, uterine rupture and several placental complications in the second delivery following a previous $\mathrm{CD}$ compared with a previous VD, are in line with other studies. ${ }^{10} 1332$ 37-42 Somewhat unexpected the proportion with abnormal invasive placenta did not differ between the two groups, which may partly be explained by the quality of this variable in the MBRN. Another explanation may be that our study was limited to adverse outcomes only in the second pregnancy, and studies have reported that abnormal invasive placenta is strongly associated with increasing numbers of CD performed. ${ }^{434}$

\section{Interpretation}

The findings regarding antepartum and total stillbirth, and perinatal death were all in the same direction, relatively precise and in line with previous literature, indicating that these findings are robust. The increased odds for cerebral palsy and the trend towards increased risk for early neonatal death were less robust. However, the number of infants with cerebral palsy was low, and the number of infants who died during delivery and in the neonatal period were even lower, and these findings should therefore be interpreted with caution.

The increased risk for any of the primary adverse outcomes in the second pregnancy may be due to placental complications, as indicated by the higher occurrence of infants born SGA, as well as a higher occurrence of placenta previa, placental abruption and pre-eclampsia compared with pregnancies without a previous CD. We speculate that the scar in the uterus after previous surgery may play a role in the development of such placental complications, for example, through suboptimal placental implantation in the following pregnancy. In addition, a scar in the uterus is a locus minoris resistentiae, increasing the risk for rupture of the uterus in the following pregnancies, as supported by the very high increased risk of uterine rupture associated with previous $\mathrm{CD}$ found in our study.
Moreover, it is well documented that placental pathology, placental abruption, pre-eclampsia, uterine rupture, preterm birth and being born SGA are all risk factors for cerebral palsy. ${ }^{45-47}$ These risk factors may be involved both in antenatal as well as in perinatal events, leading to an insult of the brain. The increased risk for cerebral palsy is also consistent with the lower Apgar score among infants born by mothers with a previous $\mathrm{CD}$, compared with those whose mothers had a previous VD, found in our study.

The trend towards increased risk for early neonatal mortality may be consistent with increased risk for intrapartum death. However, the risk for neonatal death was only slightly different between the groups, which may be reasonable due to other causes of death later in the neonatal period rather than complications during the delivery. More studies are required to investigate if and how mode of delivery in the second pregnancy may have affected this outcome.

\section{Implication}

In this population-based study from Norway, the absolute risk for stillbirth, neonatal death and cerebral palsy in the second pregnancy was low, as were the absolute risk for the secondary outcomes. Nonetheless, the increased relative risk for these complications should be included in the discussion with parents regarding mode of delivery, both when the mother requests a $\mathrm{CD}$ in the absence of a clear medical indication as well as in cases when a VD is associated with increased relative, but low absolute risk for adverse outcome. If the increased risk was entirely related to the actual mode of delivery in the second pregnancy, it might be reasonable to recommend a planned CD to all women with a previous $\mathrm{CD}$ in their subsequent pregnancy. However, this would not abolish the risk for antepartum stillbirth, SGA and preterm birth. Therefore, the main prevention of these severe complications in subsequent pregnancy may be to take individual plans for further pregnancies into account when considering $\mathrm{CD}$ without a clear medical indication. On the other hand, it should be underscored that overall, the absolute risks for stillbirth, perinatal mortality and cerebral palsy after a previous CD are indeed low in the following pregnancy.

\section{CONCLUSION}

A previous $\mathrm{CD}$ was in this study associated with increased risk for stillbirth and perinatal death compared with a previous VD. Although less robust, we also found that a previous CD was associated with a slightly increased risk of cerebral palsy among children surviving the neonatal period. The aetiology behind these associations needs further investigation.

\section{Author affiliations}

${ }^{1}$ Obstetrics and Gynecology, Helse More og Romsdal HF, Aalesund, Norway

${ }^{2}$ Department of Clinical and Molecular Medicine, Norwegian University of Science and Technology, Trondheim, Norway

${ }^{3}$ The Cerebral Palsy Registry of Norway, Habilitation Center, Vestfold Hospital, Tønsberg, Norway

${ }^{4}$ Division of Mental and Physical Health, Norwegian Institute of Public Health, Oslo, Norway

${ }^{5}$ Department of Global Public Health and Primary Care, University of Bergen, Bergen, Norway 
${ }^{6}$ Obstetrics and Gynaecology, Amager Hvidovre Hospital, Hvidovre, Denmark ${ }^{7}$ Department of Clinical Medicine, University of Copenhagen, Copenhagen, Denmark ${ }^{8}$ Regional Centre for Child and Youth Mental Health and Child Welfare, Norwegian University of Science and Technology, Trondheim, Norway

${ }^{9}$ Department of Public Health, Norwegian University of Science and Technology, Trondheim, Norway

Acknowledgements The authors thank the Cerebral Palsy Register of Norway (CPRN) and the Medical Birth Registry of Norway (MBRN) for the data. A special thanks to all the children and parents participating in the CPRN.

Contributors SB proposed the research question, analysed the data, contributed to study design and data interpretation and wrote the first draft of the manuscript. GLA was principally responsible for the data from the CPRN and revised the manuscript. LK contributed to the data interpretation and revised the manuscript. KK contributed to the study design, the analyses and interpretation of the data and revised the manuscript. SH contribute to the data interpretation and revised the manuscript. PRR contributed to the data interpretation and revised the manuscript. SL was responsible for the statistical methods, the interpretation of the results and revised the manuscript. TV contributed to the research question, the study design, the analyses and the interpretation of the data and the revision of the manuscript. All authors approved the final version of the submitted manuscript.

Funding Supported by a grant from The Liaison Committee between the Central Norway Regional Health Authority (RHA) and the Norwegian University of Science and Technology (NTNU).

Competing interests All authors have completed the ICMJE uniform disclosure form at www.icmj.org/cio_disclosure.pdf (available on request from the corresponding author) and declare: no financial support from any organisation for the submitted work; no financial relationship with any companies that might have an interest in the submitted work in the previous three years; and have no nonfinancial interests or relationships that may be relevant to the submitted work.

Patient consent for publication Not required.

Ethics approval The study was approved by the Regional Ethical Committee for Medical Research in Mid-Norway (ref 2018/2145). We intend to present results directly to the Association for persons with cerebral palsy. In addition, dissemination to the Norwegian population (which constitutes the study population) and the broader public will be achieved through media outreach or other public presentations.

Provenance and peer review Not commissioned; externally peer reviewed.

Data availability statement Data may be obtained from a third party and are not publicly available. No data are available. For question regarding the analyses of the data, please contact the corresponding author at: solveigbjellmo@gmail.com. The protocol is also available on request.

Open access This is an open access article distributed in accordance with the Creative Commons Attribution Non Commercial (CC BY-NC 4.0) license, which permits others to distribute, remix, adapt, build upon this work non-commercially, and license their derivative works on different terms, provided the original work is properly cited, appropriate credit is given, any changes made indicated, and the use is non-commercial. See: http://creativecommons.org/licenses/by-nc/4.0/.

\section{ORCID iD}

Solveig Bjellmo http://orcid.org/0000-0003-3486-2867

\section{REFERENCES}

1 Boerma T, Ronsmans C, Melesse DY, et al. Global epidemiology of use of and disparities in caesarean sections. Lancet 2018;392:1341-8.

2 Gibbons L, Belizán JM, Lauer JA, et al. The global numbers and costs of additionally needed and unnecessary caesarean sections performed per year: overuse as a barrier to universal coverage. World Health Report 2010;30:1-31.

3 Appropriate technology for birth. Lancet 1985;2:436-7.

4 Kupari M, Talola N, Luukkaala T, et al. Does an increased cesarean section rate improve neonatal outcome in term pregnancies? Arch Gynecol Obstet 2016;294:41-6.

5 Ye J, Zhang J, Mikolajczyk R, et al. Association between rates of caesarean section and maternal and neonatal mortality in the 21st century: a worldwide population-based ecological study with longitudinal data. BJOG 2016;123:745-53.
6 Molina G, Weiser TG, Lipsitz SR, et al. Relationship between cesarean delivery rate and maternal and neonatal mortality. JAMA 2015;314:2263-70.

7 Betrán AP, Ye J, Moller A-B, et al. The increasing trend in caesarean section rates: global, regional and national estimates: 1990-2014. PLoS One 2016;11:e0148343.

8 National Institute for Health and Clinical Excellence. Caesarean section (NICE clinical guideline 132), 2011. Available: https://www. nice.org.uk/guidance/CG132

9 Keag OE, Norman JE, Stock SJ. Long-term risks and benefits associated with cesarean delivery for mother, baby, and subsequent pregnancies: systematic review and meta-analysis. PLoS Med 2018;15:e1002494.

10 Daltveit AK, Tollånes MC, Pihlstrøm $\mathrm{H}$, et al. Cesarean delivery and subsequent pregnancies. Obstet Gynecol 2008;111:1327-34.

11 MBRN. Norwegian Institute of public health. Medical birth registry of Norway, 2018. Available: http://statistikkbank.fhi.no/mfr/

12 Hannah ME, Hannah WJ, Hewson SA, et al. Planned caesarean section versus planned vaginal birth for breech presentation at term: a randomised multicentre trial. Term breech trial collaborative group. Lancet 2000;356:1375-83.

13 Jackson S, Fleege L, Fridman M, et al. Morbidity following primary cesarean delivery in the Danish national birth cohort. Am J Obstet Gynecol 2012;206:139.e1-5.

14 Rageth JC, Juzi C, Grossenbacher H. Delivery after previous cesarean: a risk evaluation. Obstet Gynecol 1999;93:332-7.

15 Stoknes M, Andersen GL, Elkamil Al, et al. The effects of multiple pre- and perinatal risk factors on the occurrence of cerebral palsy. A Norwegian register based study. Eur J Paediatr Neurol 2012;16:56-63

16 Thorngren-Jerneck K, Herbst A. Perinatal factors associated with cerebral palsy in children born in Sweden. Obstet Gynecol 2006;108:1499-505.

17 O'Donovan C, O'Donovan J. Why do women Request an elective cesarean delivery for non-medical reasons? A systematic review of the qualitative literature. Birth 2018;45:109-19.

18 Hollung SJ, Vik T, Wiik R, et al. Completeness and correctness of cerebral palsy diagnoses in two health registers: implications for estimating prevalence. Dev Med Child Neurol 2017;59:402-6.

19 Cans C. Surveillance of cerebral palsy in Europe: a collaboration of cerebral palsy surveys and registers. Dev Med Child Neurol 2000;42:816-24.

20 Skjaerven R, Gjessing HK, Bakketeig LS. Birthweight by gestational age in Norway. Acta Obstet Gynecol Scand 2000;79:440-9.

21 Greenland S, Pearl J, Robins JM. Causal diagrams for epidemiologic research. Epidemiology 1999;10:37-48.

22 Lamont K, Scott NW, Jones GT, et al. Risk of recurrent stillbirth: systematic review and meta-analysis. $B M J$ 2015;350:h3080.

23 Melve KK, Skjaerven R. Birthweight and perinatal mortality: paradoxes, social class, and sibling dependencies. Int J Epidemiol 2003;32:625-32.

24 Klungsøyr K, Morken NH, Irgens L, et al. Secular trends in the epidemiology of pre-eclampsia throughout 40 years in Norway: prevalence, risk factors and perinatal survival. Paediatr Perinat Epidemiol 2012;26:190-8.

25 Aronson JK BC, Mahtani KR, Nunan D. Confounding by indication. In catalogue of biases, 2018. Available: https://catalogofbias.org/ biases/confounding-by-indication

26 Regan AK, Gissler M, Magnus MC, et al. Association between interpregnancy interval and adverse birth outcomes in women with a previous stillbirth: an international cohort study. Lancet 2019;393:1527-35.

27 Skjaerven R, Wilcox AJ, Klungsøyr K, et al. Cardiovascular mortality after pre-eclampsia in one child mothers: prospective, population based cohort study. BMJ 2012;345:e7677.

28 Lehmann S, Baghestan E, Børdahl P, et al. Validation of data in the medical birth registry of Norway on delivery after a previous cesarean section. Acta Obstet Gynecol Scand 2017:96:892-7.

29 Thomsen LCV, Klungsøyr K, Roten LT, et al. Validity of the diagnosis of pre-eclampsia in the medical birth registry of Norway. Acta Obstet Gynecol Scand 2013;92:943-50.

30 Al-Zirqi I, Stray-Pedersen B, Forsén L, et al. Validation study of uterine rupture registration in the medical birth registry of Norway. Acta Obstet Gynecol Scand 2013;92:1086-93.

31 Osborne C, Ecker JL, Gauvreau K, et al. First birth cesarean and risk of antepartum fetal death in a subsequent pregnancy. J Midwifery Womens Health 2012;57:12-17.

32 Kennare R, Tucker G, Heard A, et al. Risks of adverse outcomes in the next birth after a first cesarean delivery. Obstet Gynecol 2007;109:270-6. 
33 Gray R, Quigley MA, Hockley C, et al. Caesarean delivery and risk of stillbirth in subsequent pregnancy: a retrospective cohort study in an English population. BJOG: Int J Obstet Gy 2007;114:264-70.

34 Smith GCS, Pell JP, Dobbie R. Caesarean section and risk of unexplained stillbirth in subsequent pregnancy. Lancet 2003;362:1779-84.

35 Moraitis AA, Oliver-Williams C, Wood AM, et al. Previous caesarean delivery and the risk of unexplained stillbirth: retrospective cohort study and meta-analysis. BJOG: Int J Obstet Gy 2015;122:1467-74.

36 Rageth JC, Juzi C, Grossenbacher H. Delivery after previous cesarean: a risk evaluation. Swiss working group of obstetric and gynecologic institutions. Obstet Gynecol 1999;93:332-7.

37 Taylor LK, Simpson JM, Roberts CL, et al. Risk of complications in a second pregnancy following caesarean section in the first pregnancy: a population-based study. Med J Aust 2005;183:515-9.

38 Hemminki E, Shelley J, Gissler M. Mode of delivery and problems in subsequent births: a register-based study from Finland. Am J Obstet Gynecol 2005;193:169-77.

39 Getahun D, Oyelese Y, Salihu HM, et al. Previous cesarean delivery and risks of placenta previa and placental abruption. Obstet Gynecol 2006;107:771-8.
40 Downes KL, Hinkle SN, Sjaarda LA, et al. Previous prelabor or intrapartum cesarean delivery and risk of placenta previa. $A m \mathrm{~J}$ Obstet Gynecol 2015;212:669.e1-6.

41 Salihu HM, Bekan B, Aliyu MH, et al. Perinatal mortality associated with abruptio placenta in singletons and multiples. Am J Obstet Gynecol 2005;193:198-203.

42 Gurol-Urganci I, Cromwell DA, Edozien LC, et al. Risk of placenta previa in second birth after first birth cesarean section: a populationbased study and meta-analysis. BMC Pregnancy Childbirth 2011;11:95

43 Silver RM, Landon MB, Rouse DJ, et al. Maternal morbidity associated with multiple repeat cesarean deliveries. Obstet Gynecol 2006;107:1226-32.

44 Wu S, Kocherginsky M, Hibbard JU. Abnormal placentation: twentyyear analysis. Am J Obstet Gynecol 2005;192:1458-61.

45 Nelson KB, Blair E. Prenatal factors in singletons with cerebral palsy born at or near term. N Engl J Med 2015;373:946-53.

46 Vik T, Redline R, Nelson KB, et al. The placenta in neonatal encephalopathy: a case-control study. J Pediatr 2018;202:77-85.

47 Mclntyre S, Taitz D, Keogh J, et al. A systematic review of risk factors for cerebral palsy in children born at term in developed countries. Dev Med Child Neurol 2013;55:499-508. 